\title{
Influence of Students Perception/Staff Attitude in the Clinical Areas on Student's Learning in Mathare Teaching and Referral Hospital, Nairobi, Kenya
}

\author{
Evangeline Kananu Njue Mugoh*, Mary Wanjira Njue Kamau \\ School of Health Sciences, Regina Pacis University College, Catholic University of Eastern Africa, Nairobi, Kenya
}

Email address:

evangelinemugoh@gmail.com (E. K. N. Mugoh), kwanjira@uonbi.ac.ke (M. W. N. Kamau)

${ }^{*}$ Corresponding author

\section{To cite this article:}

Evangeline Kananu Njue Mugoh, Mary Wanjira Njue Kamau. Influence of Students Perception/Staff Attitude in the Clinical Areas on Student's Learning in Mathare Teaching and Referral Hospital, Nairobi, Kenya. American Journal of Nursing Science.

Vol. 9, No. 2, 2020, pp. 47-54. doi: 10.11648/j.ajns.20200902.11

Received: October 18, 2019; Accepted: November 28, 2019; Published: February 13, 2020

\begin{abstract}
Clinical learning environment is a very important aspect of nursing teaching. In Europe as well as USA, the principle of nursing education is based on a $50 \%$ theoretical class work and $50 \%$ practical through clinical experience. In Kenya, the learning is different where $69.5 \%$ is class work and $21.5 \%$ is the clinical area placement. Kenya government designed a one-year internship for all $\mathrm{BScN}$ students before they are entered into nursing council register to give the student enough experience before they enter into the field. Clinical learning is described as the "heart" of professional practice. Practice placement constitutes an important aspect of students' learning through influencing students' acquisition of skills and knowledge for quality care provision in the right environments. The future of nursing profession is based on capacitating the student nurse with the ability to make critical decision at work. Noteworthy, many aspects affect student learning in clinical placement. Among them is shortage of qualified staff which is the case in the study area- Mathare Teaching and Referral Hospital. This study focused on factors that influence students learning in the clinical placement and aimed to determine the effect of student's perspectives and staff attitude towards learning in placement areas on learning among bachelor of nursing $(\mathrm{BScN})$ students. A self-administered questionnaire was used to collect data that was analyzed by using statistical package of social sciences (SPSS) version 20. Study findings were presented by use of tables, charts and text. The findings revealed that most students $(64.8 \%)$ were pursuing nursing training out of individual choice and felt that nursing was a calling to them but some (25.9\%) would go to another career given a chance. Most (61.1\%) students were apprehensive about clinical placement and the work they would be involved in. Reception in the hospital department by supervision staff was generally fairly satisfactory however 5.6\% students reported lack of satisfaction. Nursing staff in the clinical area were generally friendly and concerned; and staff supervision in the clinical area was generally helpful and caring but not always available. The clinical placement areas need to enhance nurse-under-placement and receptors relationship to enhance uptake of the real life experience of the nursing profession.
\end{abstract}

Keywords: Student's Perspectives, Staff Attitude, Nursing-Student's Learning, Clinical Learning Environment

\section{Introduction}

\subsection{Background Information}

Nursing is referred to as a practice-based profession in many parts of the world. This is the case in the United States of America, Australia, New Zealand and European countries, such as the United Kingdom (UK) and Finland where clinical teaching and learning form a significant part of preregistration nursing training and education programmes [1]. In these countries, clinical learning plays an important role in improving the practice of both healthcare professionals and student nurses, which in turn contributes to improve care provision. Clinical learning is described as the "heart" of professional practice [2].

The extent to which newly qualified nurses are adequately 
prepared for the responsibilities of their first post is a key concern for prospective employers and for the service and education staff charged with responsibility for student nurse education [3]. Students ' knowledge and skill acquisition, and theory- practice integration can be enhanced through mentorship activities [4]. In Kenya, one of the major components of student nurse preparation is mentorship; the process by which a student nurse (mentee) during periods of practical experience (placements) is attached to a qualified nurse (mentor) who guides the student's practice, assesses their progress, and judges their competence before being registered in the Nursing Council of Kenya (NCK) [5]. Mentorship has long been regarded as the cornerstone of nurse education and, as such, the experience of both mentor and mentee has been the focus of a considerable volume of research.

Clinical learning is where student nurses are allowed to interact with real patient and real situation in the clinical area and practice what they learnt in class working while being supervised by a qualified nurse. Clinical setting is described as a clinical classroom [6]. One of the most valuable components of a nursing program is the clinical learning environment (CLE). This setting provides students with unique learning opportunities in which classroom theory and skills are put to test with real life situations. CLEs include hospital wards, consultant doctor's clinics in the hospital' theatre, special clinics in the hospital, comprehensive care clinics/patients support clinics, maternal and child welfare clinics and other health care settings utilized for student learning. The CLE differs from the classroom or lab setting in many ways [7].

This study is anchored on social learning theory which can be defined by behavior modeling or observational learning that comprises of motor reproduction, motivation, and retention [8]. Importantly, behavior is subjective to places of learning which in this case is CLE [9]. The CLE is a complex social entity that influences student learning outcomes in the clinical setting. Exploration of this environment gives insight into the educational functioning of the clinical areas and allows nurse teachers to enhance students' opportunities for learning.

The CLE is unpredictable and relatively out of the nursing instructor's control. Staff members, unit environment, equipment and supplies, census, and patients and family members are elements of the CLE that cannot be controlled by instructors [10]. This unpredictable environment can be a major shock for students compounded by difficulty and confusion in the transition from student-learner to studentlearner-worker. Staff members may view students as workers only, especially when patient care demands are high. Nursing students are taught to provide holistic care but at times may be faced with more technical tasks than holistic patient care [11].

WHO recommends provision and maintenance of appropriate clinical learning facilities including workbooks, curriculum, manuals, nursing standard guidelines, reading material, computer, portable video 'recorders, pamphlets, equipment and supplies [12]. Nursing procedures should be standardized in order to facilitate nursing care and clinical teaching as well as clinical instructors must be provided with an outline of the clinical education programme [13]. A clinical environment includes everything that surrounds the nursing work, including the clinical settings, the staff and the patients [14].

The attitude of nursing students toward clinical work is a topic of interest for research [15]. The clinical learning environment has been shown to have a direct impact on nursing student's perception of their profession and facilitates professional grounding [12]. Importantly, attitude plays a major role in guiding human behavior toward achieving goals, awareness of its consequences and effective processing of complex information about living environment.

The quality of the clinical learning environment is an essential factor in determining the quality of nursing students' clinical experience and outcome and the qualified professional nurse later in the development of the profession. It is well recognized that clinical setting can be of stress and anxiety hence deterring proficiency [16]. Clinical studies in nursing education are reported to represent the most stressful parts for the students, particularly in the initial stages due to lack of competence and knowledge [17]. The relationship between nursing staff and student nurses is the key component in clinical practice. Collegial relationships with the staff are an important element in student nurses' learning and socialization. [18]. The accompanist for student nurses should develop strategies to build trust and create a caring environment. Such an environment enhances clinical learning for the student nurses. Student nurses should be supported in addressing and overcoming fear and anger, so as to provide quality nursing care. Support should also be given to student nurses to enable them to identify and handle conflict associated with caring for patients [19].

\subsection{Problem Statement}

Since training of nurses started in the 1950s, there has been progressive increase in number of institutions training nurses and nurses being trained under the same management [20]. As of 2012, NCK reported 82 accredited nurse training institutions, of whom 10 were opened between year 2010 and 2012. Together these institutions offered 19 BSc. $\mathrm{N}$ programmes across Kenya with about $8.3 \%$ students having gone through BSc. N in the Kenya by 2012 [7].

On the contrary, clinical placement areas and resources have not increased at a similar rate. In the late 1980s the nursing schools were given autonomy. Nursing schools have to get a memorandum of understanding (MOU) with the hospital for students' placement at some fee. The MOU increased chances of clinical placement of students from private institutions compared with their counter parts in public nursing institutions [20]. The unmatched increase in number of nursing-students clinical placement areas has caused over-stretch of the clinical resources therefore adversely affecting student's learning. Influx of students reduced effectiveness of follow up of students in the 
placement areas. Additionally, shortage of nurses in the health facilities negatively impacts on supervisory roles, student learning time, and consequently patient care [10]. The basis of the principles of nursing education worldwide are $50 \%$ class work and $50 \%$ clinical experience which is not the case in Kenya [21]. This study aimed to assess how student's perspectives and staff attitude may have influenced clinical learning of the students.

\subsection{Objective}

1. To determine the effect of BScN students' perception on learning in the clinical area at Mathare Teaching and Referral Hospital.

2. To determine the effect of staff attitude on learning of the BScN students in Mathare Teaching and Referral Hospital.

\section{Literature Review}

\subsection{Clinical Practice}

Clinical placement in many part of the world is the base of training for $\mathrm{BScN}$. In the Norwegian for example, the bachelor of nursing, students are assigned to clinical placements for $42 \%$ of the total education time. These placements are defined as supervised practice in which case students are preceptored by a registered nurse [22]. In Kenya, the BSCN students have more time in class $(69.9 \%$ class work) and slightly less time in clinical practice (29.1\%) clinical practice. Students learn more of clinical practice and undertake nursing council licensing examination during one year of internship after graduation from college. This is presumed to contribute to the presence of unregistered nurses in the Kenyan market [7].

\subsection{Student Perception}

There has been a rise in the negative attitude displayed by nursing students as well as nurses toward the nursing profession due to unpleasant hard work in the hospital, working on holidays, lack of respect for work, and low salary [23]. Loss of nurses' interest in what they do, not only negatively affects the quality of work, but also demoralize the profession [1].

\subsection{Attitude of Staff}

Qualified staff should treat student nurses with kindness and understanding, and should try to show interest in them as people. They should be approachable, helpful, provide student nurses with necessary support, and try to foster student nurses' self-esteem. Qualified staffs need to be sensitive to the study needs of the student nurses [22]. Caring as an important element for maintaining positive relationships by both the student nurses and faculty, and was perceived as an important aspect of the student nurses' learning experiences [18].

The triad model of the ideal teaching relationship, where the teacher plays a supportive role and provides learning opportunities for student nurses, as a facilitator of learning [24]. This relationship is vital if student nurses' clinical learning experiences are to be maximized. Such a teacher must be willing to be less of an advice-giver and rescuer than one who facilitates the student nurses' exploration of nursing practice [25].

Lack of separation of roles results in the development of an inappropriately balanced relationship, wherein the teacher fosters student nurses' dependence, which adversely affects the student nurses' learning experience. Another negative aspect in this model is where the teacher consistently and inappropriately takes over the responsibility for client care from the student nurses, and by so doing, depriving the student nurses of the opportunity of practice and clinical decision-making [24].

There is a health care crisis resulting from a shortage of nurses in the workforce and the shortage impacts upon nurses' workloads by creating increased responsibilities [26]. The increased responsibility of nursing students may add to the already existing stress in the work setting. As nursing educators recognize the need to prepare a competent, dedicated nursing workforce for the future, it is imperative that nursing schools retain students and facilitate a positive effective learning environment within the clinical practice setting.

Nursing students encounter a wide range of support from being treated very badly to very good depending on the staffing and attitudes of the nurses [27]. Often the students feel that when there are staffing shortages, they are being exploited, as just a pair of hands to get the work done and their learning objective is not important.

\section{Methodology}

This was a cross sectional descriptive research study that utilized quantitative approach. Study site was Mathare Teaching and Referral Hospital. Study population was 63 $\mathrm{BScN}$ students in clinical areas and in placement at the time of data collection. A sample of 54 students was selected using stratified sampling technique. Five different learning institutions formed strata. Data was collected using selfdirected structured questionnaires. Quality control measures were employed including pre-test, validity and reliability checks.

Approval to conduct research was obtained from Regina Pacis University, Kenyatta National Hospital Ethical Review Committee; and clearance from Mathare Teaching and Referral Hospital. Respondents consented to participate with confirmation of confidentiality. Collected data was crosschecked for completeness and any missing entries corrected upon completion of each interview.

Data coding, entry and analysis was done using SPSS version 20 software. Descriptive data analysis included frequencies and percentages. Findings were presented as text, graphs and tables. 


\section{Findings and Discussion}

\subsection{Social Demographic Data}

The study sample comprised majorly of females who were in $3^{\text {rd }}$ and $4^{\text {th }}$ year of studies, Table 1 .

Table 1. Socio-demographic characteristics.

\begin{tabular}{llll}
\hline Variable & Categories & Frequency & Percent \\
\hline \multirow{2}{*}{ Gender } & Female & 35 & 64.8 \\
& Male & 18 & 33.3 \\
Year of study & 2 & 10 & 18.5 \\
& 3 & 25 & 46.3 \\
Year of entry to & 4 & 18 & 33.3 \\
training & 2011 & 5 & 9.3 \\
& 2012 & 18 & 33.3 \\
& 2013 & 23 & 42.6 \\
Marital status & 2014 & 3 & 5.6 \\
& Single & 43 & 79.6 \\
& Married & 9 & 16.7 \\
\hline
\end{tabular}

\subsection{Perception of Clinical Placement on Learning}

The greatest proportion (64.8\%) students did nursing training as an individual choice and felt that nursing was a calling. A group of $18.5 \%$ students followed the interest of their parents. Section of $25.9 \%$ and $9.3 \%$ would go to another career given a chance and were not sure about the interest in nursing respectively.

Similar findings were made in a study among newly admitted students to campuses in Kenya where they observed that majority $(46.3 \%)$ of the students were not influenced to pursue nursing career; while $22.7 \%$ were influenced by qualified nurses, $16.3 \%$ influenced by parents [23]. Contrary findings were among Chinese students whose decisions to choose nursing was usually made by their parents or influenced by other people with some of the students studying nursing as a major due to being transferred from other majors [28]. The parents, the school teachers, friends, past experiences with career activities and working in hospital were some of the influences that made the students in Hong Kong to have the intent to study nursing [29].

Table 2. Nursing profession perception.

\begin{tabular}{llll}
\hline Attribute & & Frequency & Percent \\
\hline \multirow{3}{*}{$\begin{array}{llll}\text { Reason for nursing } \\
\text { training }\end{array}$} & Individual choice & 35 & 64.8 \\
& Parent's interest & 10 & 18.5 \\
& The only better option & 8 & 14.8 \\
& Friend's influence & 1 & 1.9 \\
Perception about & Feel it is a calling & 35 & 64.8 \\
nursing & Given chance would go & 14 & 25.9 \\
& for another career & 5 & 9.3 \\
\hline
\end{tabular}

Most 33 (61.1\%) students were apprehensive about clinical placement and the work they would be involved in, 11 $(20.4 \%)$ didn't know what they expected while 8 (14.8\%) were anxious and $2(3.7 \%)$ feared the staffs they would meet. Majority 24 (44.4\%) students thought of the staff working in the hospital before their placement to be friendly. On the contrary, $21(38.9 \%)$ students thought the staff in hospital would not care or help in learning, $8(14.8 \%)$ thought they would be hostile and $1(1.9 \%)$ thought that they wouldn't help in learning.

Similar findings were expressed by psychiatric student in one of the hospital in Kenya where they felt psychiatric nursing is associated with stigma and luck of motivation [30]. Similar findings were made among Norwegian students which reviewed that the students expressed their anticipations about how they expected to be received by the Bangladeshi nurses and how they expected to achieve their learning objectives during their clinical placement. Initially these mentioned apprehensions about, on the one hand, being excluded from performing 'hands on' clinical practice and on the other hand, being expected to perform 'hands on' clinical practice without relevant preparation and guidance [31]. Similar findings were also made among Australian students where the study demonstrated students' negative emotions or feelings towards clinical placement in a high-acuity setting but the student confidence to perform individual clinical skills increased over the semester; however their feelings of preparedness for high-acuity clinical placement decreased over the same time period [32].

Table 3. Perception of placement environment.

\begin{tabular}{llll}
\hline Attribute & & Frequency & Percent \\
\hline Perception about & Apprehensive & 33 & 61.1 \\
clinical & Didn't know what to expect & 11 & 20.4 \\
placement and & Anxious & 8 & 14.8 \\
work involved in & Fear of the staffs & 2 & 3.7 \\
& Friendly & 24 & 44.4 \\
Perception on & Won't help in learning & 21 & 38.9 \\
before placement working & Hostile & 8 & 14.8 \\
& Won't care about learning & 1 & 1.9 \\
\hline
\end{tabular}

Majority $26(48.10 \%)$ students were placed in males wards, $24(44.4 \%)$ in female wards, $9(16.7 \%)$ in OPD, 7 $(13.0 \%)$ in special clinics, $4(7.4 \%)$ in rehab and $1(1.9 \%)$ dressing /injection rooms and occupational therapy.

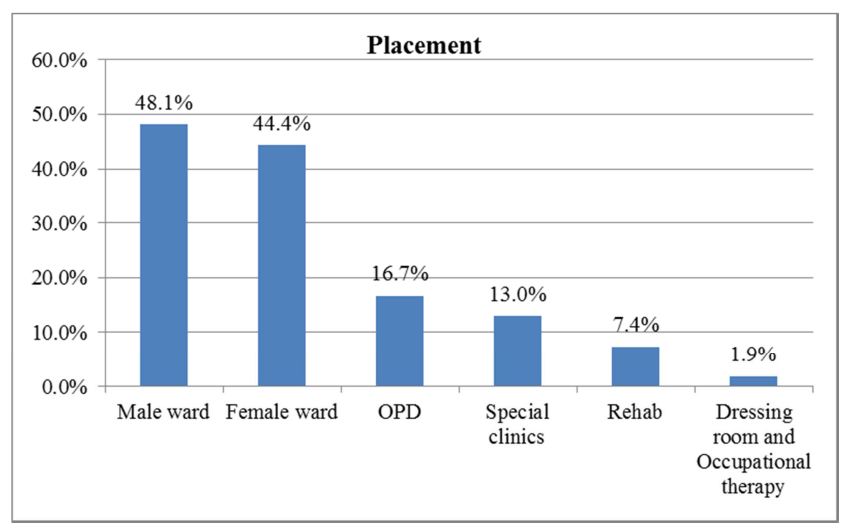

Figure 1. Placement locations.

The overall rating of the clinical areas was $63 \%$ which implied that the students considered the clinical area to be good. Majority $18(33.3 \%)$ students reported that the clinical areas were good, $16(29.6 \%)$ reported they were fairly good and $10(18.5 \%)$ reported that they were fair and very good 
each.

Similar findings were made among nursing students on placement at teaching and referral hospitals in Kenya in which it was found out that they were able to take initiative in their training and meet clinical objectives but were dissatisfied with unavailability of procedure manuals for reference at clinical sites [33]. Similar findings observed that most nursing students in placement were more satisfied than dissatisfied with the learning environment in the nursing homes [19].

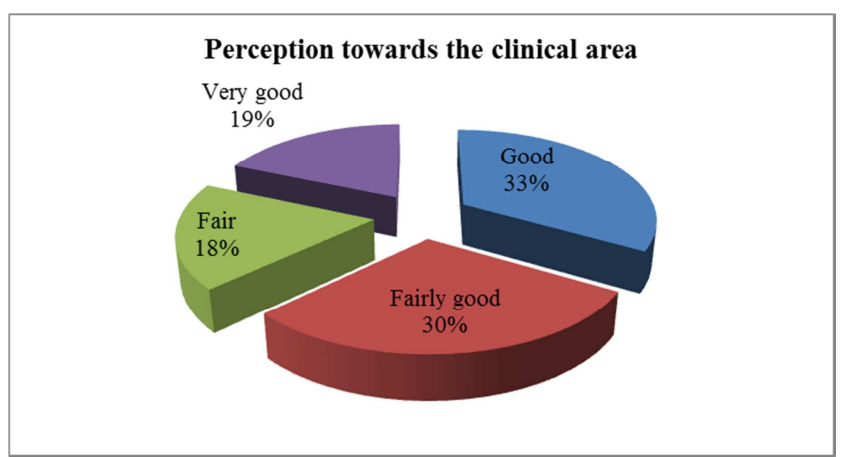

Figure 2. Perception towards the clinical area.

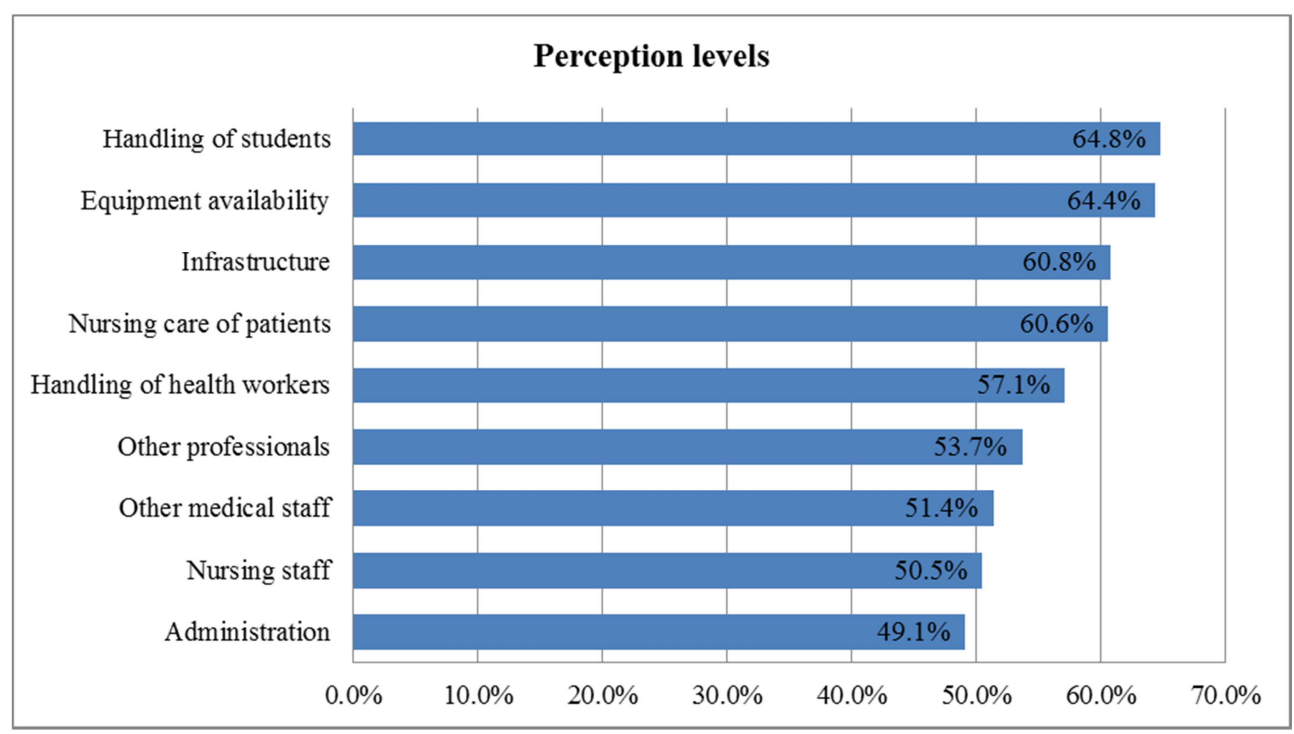

Figure 3. Perception levels on issues.

An assessment of the perception on various issues evaluated on a percentage of the average established that nursing staff were fair $(50.5 \%)$; other medical staff were fair $(51.4 \%)$; other professionals were fair $(53.7 \%)$; administration was fair (49.1 nursing care of patients was fair (60.6\%); handling of health workers was fair $(57.1 \%)$ and handling of the students was fairly good (64.8\%).

Contrary findings were made among students in placement in rural hospitals in South Africa where it was found out that the nursing students experienced lack of support, inadequate mentoring and guidance, isolation from clinical activities, an inhumane attitude by clinical staff, a poor clinical environment and many other aspects as hindering students' learning [34]. Similarly, students expressed most satisfaction with peer collaboration, the placement's contribution to awareness of future nursing role and described the learning arena as exciting and interesting [19].

\subsection{Nursing Staff Attitude Towards Supervision and Learning of BScN Students}

Reception in department by supervision staff was generally fairly satisfactory however $3(5.6 \%)$ students reported lack of satisfaction. Nursing staff in the clinical area were generally friendly and concerned however $11(20.4 \%)$ and $7(13.0 \%)$ students reported staff as indifferent and unfriendly.

Similar findings were made in mental health facilities in Kenya in which it was observed that most $(90.8 \%)$ students commended the nursing staff for being responsive to their requests for assistance and $89.1 \%$ enjoyed their placement [30]. Contrary findings indicated that students often perceive mentors to be too busy to provide the required level of support in United Kingdom [35]. This can lead to increased levels of anxiety for students as they may feel unsupported. Mentors are one of the critical factors affecting students' ability to learn and cope on their placements. Similarly, students expressed less satisfaction with supervision from preceptor and how the practice site was prepared for and organized students' placements [19].

Staff supervision in the clinical area was generally helpful and caring but only available a few times however 4 (7.4\%) students reported that the staff didn't care about learning respectively. Clinical staffs were generally availability for help in learning when needed and helpful in the process of learning. However $4(7.4 \%)$ and $5(9.3 \%)$ students reported that the staff were not available at all and were not helpful in the process of learning respectively.

Similar findings were made among nursing students on placement in a mental health facilities in Kenya in which it 
was observed that there was shortage of staff of whom majority were not trained in mental health and tended to concentrate on giving service rather than assisting students thus interfering with mentorship [30]. Contrary findings were made among Norwegian nursing students where it was found out that students highly valued teachers' and preceptors' supervision, although teachers' supervision was rated somewhat more highly. Fulfillment of learning outcomes for clinical practice was also rated highly, and the teachers' supervision was estimated, to some extent, more highly than the preceptors' supervision in this respect [36]. Similar, students in nursing homes found it less easy to approach the staff as compared to students in hospital placements which was attributed to the fact that nursing homes in Norway are often lower staffed than hospitals, perhaps resulting in nursing students feeling that they were a disturbance when and if approaching nurses [37].

Table 4. Nursing staff attitude towards supervision and learning of BSCN.

\begin{tabular}{|c|c|c|c|c|}
\hline Attribute & Categories & Frequency & Percent & Median \\
\hline \multirow{4}{*}{$\begin{array}{l}\text { Reception in department by } \\
\text { supervision staff }\end{array}$} & Satisfactory & 23 & 42.6 & \multirow{4}{*}{ Fairly satisfactory } \\
\hline & Fairly satisfactory & 17 & 31.5 & \\
\hline & Very satisfactory & 10 & 18.5 & \\
\hline & Unsatisfactory & 3 & 5.6 & \\
\hline \multirow{3}{*}{$\begin{array}{l}\text { Perception on nursing staff in the } \\
\text { clinical area }\end{array}$} & Friendly and concerned & 30 & 55.6 & \multirow{3}{*}{ Friendly and concerned } \\
\hline & Indifferent & 11 & 20.4 & \\
\hline & Unfriendly & 7 & 13.0 & \\
\hline \multirow{4}{*}{ Staff supervision in the clinical area } & Helpful and caring but not always there for your & 22 & 40.7 & \multirow{4}{*}{$\begin{array}{l}\text { Helpful and caring but only } \\
\text { available a few times }\end{array}$} \\
\hline & Helpful and caring but only available a few times & 18 & 33.3 & \\
\hline & Very helpful, caring and always there & 9 & 16.7 & \\
\hline & Didn't care about learning & 4 & 7.4 & \\
\hline \multirow{3}{*}{ Availability for help in learning } & Always available when needed & 32 & 59.3 & \multirow{3}{*}{$\begin{array}{l}\text { Always available when } \\
\text { needed }\end{array}$} \\
\hline & 1 day in a week & 12 & 22.2 & \\
\hline & 2 days in a week & 5 & 9.3 & \\
\hline Helpfulness in learning process & Not helpful & 5 & 9.3 & Helpful \\
\hline
\end{tabular}

Ward activities mainly included doctors rounds $44(83.0 \%)$, nursing rounds $44(83.0 \%)$, bed making 17 (32.1\%), drug administration $39(73.6 \%)$, collecting specimens $39(73.6 \%)$ and ward managements $30(56.6 \%)$.

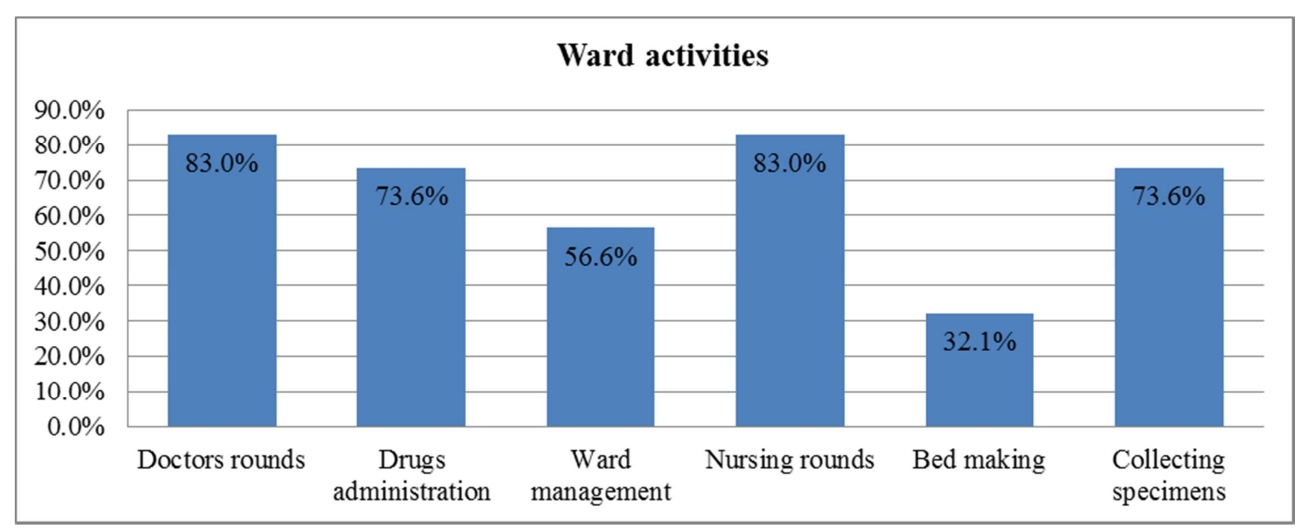

Figure 4. Perception towards Ward activities.

A proportion of $35(64.8 \%)$ students felt that the trained nurses positively influenced their learning in the clinical area by guidance, $16(30.2 \%)$ practical / adequate examples 7 (13.2\%); positive attitude 6 (11.3\%); motivation 5 (9.4\%); encouragement 4 (7.5\%); supportive 4 (7.5\%); availability $3(5.7 \%)$; helpful $1(1.9 \%)$; caring 1 $(1.9 \%)$ and patient mobilization 1 (1.9\%). However 1 $(1.9 \%)$ reported negative influence as a result of staff not being helpful.

\section{Conclusion}

Most students pursued nursing training as an individual choice with the feeling of a calling to them. Some of the students give an indication of being in the 'wrong' career with high chances of exiting nursing. Most students were apprehensive about clinical placement and the work they would be involved. Staff working in the hospital before student placement were mostly presumed to be friendly. In this study, the reception by supervision staff was fairly satisfactory. Nursing staff in the clinical area were generally friendly and concerned. Staff supervision in the clinical area was generally helpful and caring. Availability of staff supervision in the clinical area poses as a challenge to the student nurses. 


\section{Recommendation}

All clinical learning stakeholders need to collaborate to ensure that all needed equipment and staff are available.

There is need for proper sensitization of would-be nurse trainees on career choices as it has been shown that some of the nurses, although few, were pursuing the nursing profession following the interest of their parents and even some of them were considering changing profession if granted a chance to do so. This implies that these students had negative attitude towards nursing which is considered a 'calling' profession.

There is also need for proper preparation of students prior to placement to alley their apprehension during this practice.

The clinical placement areas need to enhance nurse-underplacement and receptors relationship as this will enhance uptake of the real life experience of the nursing profession since some students' perceived supportive but rarely available supervision especially in the clinical area.

\section{List of Abbreviations}

$\begin{array}{ll}\text { BScN } & \text { Bachelor of Science in nursing. } \\ \text { CLE } & \text { Clinical Learning Environment. } \\ \text { NCK } & \text { Nursing council of Kenya } \\ \text { SPSS } & \text { Statistical Package for Social Sciences }\end{array}$

\section{Declarations}

\section{Ethics Approval and Consent to Participate}

The study was performed under protocol approved by Regina Pacis University, Kenyatta National Hospital Ethical Review Committee; and clearance from Mathare Teaching and Referral Hospital.

\section{Consent for Publication}

Not applicable.

\section{Availability of Data and Material}

The datasets used and/or analyzed during the current study are available from the corresponding author on reasonable request.

\section{Competing Interests}

The authors declare that they have no competing interests.

\section{Funding}

This study was fully funded by the Corresponding Author

\section{Authors' Contributions}

Authors made substantial contributions to conception and design, and/or acquisition of data, and/or analysis and interpretation of data.

\section{Acknowledgements}

The authors of this publication "Influence of Student's Perspectives and Staff Attitude in the Clinical Areas on Student's Learning in Mathare Teaching and Referral Hospital, Nairobi, Kenya." would like to thank Regina Pacis University; Kenyatta National Hospital and Mathare Teaching and Referral Hospital; and Exactitude Research Consultants for their contributions.

\section{References}

[1] T. D. Barton, "The integration of nursing and midwifery education within higher education: implications for teachers-a qualitative research study," Journal of Advanced Nursing, 27 (6), p. 1278-1286, 1998.

[2] Å. Bergland and H. Lærum, "Norwegian nursing students' views on nursing homes as workplace after graduation," Nordic Journal of Nursing Research, 22, pp. 21-26, 2002.

[3] R. M. Harden, "Techniques of identifying competencies needed by doctors," Medical Teacher, 7 (1), pp. 15-25, 2004.

[4] W. S. Barnett, D. J. Epstein, M. E. Carolan, J. Fitzgerald, D. J. Ackerman and A. H. Friedman, The State of Preschool 2010: State Preschool Yearbook, Rutgers The State University of New Jersey: National Institute for Early Education Research, 2010 .

[5] NCK, Standards of nursing education and practice for nurses in Kenya. 2nd ed., Nairobi: Nursing Council of Kenya, 2009.

[6] P. Serena and B. Anna, "Italian nursing students' perception of their clinical learning environment as measured with the CLEI tool," Nurse Education Today, 29 (8), pp. 886-890, 2009.

[7] A. Appiagyei, R. Kiriinya and M. Rogers, "Informing the scale-up of Kenya's nursing workforce, a mixed methods study of factors affecting pre-service training capacity and production," Human resource for health 2014, 1247, 2014.

[8] F. Schmalleger, "The crime picture," Criminal Justice Today: An Introductory Text for the 21st Century, pp. 30-63, 2009.

[9] S. Hamby, "The second wave of violence scholarship: Integrating and broadening theories of violence," Psychology of violence, 1 (3), p. 163, 2011.

[10] K. B. Gaberson and M. H. Oermann, Clinical teaching strategies in nursing (2nd ed.), New York: Springer Publishing, 2012.

[11] P. Pearcey, "Tasks and routines in 21st century nursing: student nurses' perceptions," British Journal of Nursing, 16 (5), pp. 296-300, 2007.

[12] C. A. Nolan, "Learning on clinical placement: the experience of six Australian student nurses," Nurse education today, 18 (8), pp. 622-629, 1998.

[13] C. Elisabeth, W. H. Christine and P. Ewa, "Teaching during clinical practice: Strategies and techniques used by preceptors in nursing education," Nurse education today, 29 (5), pp. 522526, 2009. 
[14] I. Papp, M. Markkanen and M. von Bonsdorff, "Clinical environment as a learning environment: student nurses' perceptions concerning clinical learning experiences," Nurse education today, 23 (4), pp. 262-268, 2003.

[15] K. Kleehammer, A. L. Hart and J. F. Keck, "Nursing students' perceptions of anxiety-producing situations in the clinical setting," Journal of Nursing Education, 29 (4), pp. 183-187, 1990.

[16] B. M. Melnyk and E. Fineout-Overholt, Evidence-based practice in nursing \& healthcare: A guide to best practice, Lippincott Williams \& Wilkins, 2011.

[17] L. Wilson-Thomas, "Applying critical social theory in nursing education to bridge the gap between theory, research and practice," Journal of Advanced Nursing, 21 (3), pp. 568-575, 1995.

[18] M. Saarikoski and T. Warne, "Clinical learning environment and supervision: testing a research instrument in an international comparative study," Nurse education today, 22 (4), pp. 340-349, 2002.

[19] G. Brynildsen, I. T. Bjørk, K. Berntsen and M. Hestetun, "Improving the quality of nursing students' clinical placements in nursing homes: An evaluation study," Nurse Education in Practice, 14 (6), vol. 14, no. 6, p. 722-728, November 2014.

[20] R. Chapman and A. Orb, "The nursing students' lived experience of clinical practice," The Australian electronic journal of nursing education, 5 (2), pp. 1-16, 2000.

[21] J. Hopton, "Reconceptualizing the theory-practice gap in mental health nursing," Nurse Education Today, 16 (3), pp. 227-232, 1996.

[22] T. Djork, K. Bentsen, G. Brynildsen and M. Hestetun, "Nursing students perceptions of their clinical learning environment in placement outside traditional hospital settings," Clinical nursing Journal. J clin Nurs, 2014 Oct, 23 (19-20), pp. 2958-2967, 2014.

[23] C. N. Kabanya and K. P. Mwaniki, "Factors Influencing the Choice of Nursing Career among Newly Admitted Nursing Students in Campuses of Medical Training institutions in Kenya," 2013.

[24] L. S. Shulman, "Taking learning seriously," Change: The Magazine of Higher Learning, 31 (4), pp. 10-17, 1999.

[25] M. Saarikoski, H. Isoaho, T. Warne and H. Leino-Kilpi, "The nurse teacher in clinical practice: developing the new subdimension to the clinical learning environment and supervision (CLES) scale," International journal of nursing studies, 45 (8), p. 1, 2008.
[26] D. J. Middaugh and P. E. Thompson, "Nursing students benefit your facility," Medsurg Nursing, 16 (6), pp. 408-411, 2007.

[27] A. Hewison and S. Wlldman, "The theory-practice gap in nursing: A new dimension," Journal of Advanced Nursing, 24 (4), pp. 754-761, 1996.

[28] M. Zhang and M. Petrini, "Factors influencing Chinese undergraduate nursing students' perceptions of the nursing profession," International Nursing Review, 55 (3), vol. 55, no. 3, p. 274-280, 2008.

[29] W. Law and D. Arthur, "What factors influence Hong Kong school students in their choice of a career in nursing," International Journal of Nursing Studies, 40 (1), vol. 40, no. 1, pp. 23-32., 2003.

[30] E. Oywer, "Career in Mental Health Nursing: The Kenyan Experience," 2011.

[31] W. Jørgensen and H. Hadders, "The significance of communities of practice: Norwegian nursing students' experience of clinical placement in Bangladesh," Nursing Open, 2 (1), vol. 2, no. 1, pp. 36-46, 6 April 2015.

[32] J. Porter, J. Morphet, K. Missen and A. Raymond, "Preparation for high-acuity clinical placement: confidence levels of final-year nursing students," Advances in medical education and practice, 4, vol. 4, p. 83-89, 30 April 2013.

[33] E. Nyangena, A. Mutema and A. Karani, "Evaluation of Clinical Training in Nursing in Kenya," Baraton Interdisciplinary Research Journal, vol. 1, no. 2, pp. 22 - 30, 2011.

[34] S. R. Rikhotso, M. J. Williams and G. d. Wet, "Student nurses' perceptions of guidance and support in rural hospitals," Curationis, vol. 37, no. 1, 19 November 2014.

[35] V. Emmanuel, "Creating supportive enviroment for students," Nursing Times, vol. 109, no. 37, pp. 18-20, 18 September 2013.

[36] A. Löfmark, K. Thorkildsen, M.-B. Råholm and G. K. Natvig, "Nursing students' satisfaction with supervision from preceptors and teachers during clinical practice," Nurse Education in Practice, vol. 12, no. 3, p. 164-169, 6 January 2012.

[37] M. W. Skaalvik, H. K. Normann and N. He, "Clinical learning environment and supervision: experiences of Norwegian nursing students. A questionnaire survey," University Tromsø., Norway., 2009. 